\section{The European professional phlebologist}

\section{Alessandro Frullini \\ Associazione Flebologica Italiana, Figline Valdarno (FI), Italy}

What is phlebology? Who are the phlebologists? These could seem obvious questions but the answer may not be so simple.

The peculiarity of phlebology is that this deals with a very common disease that crosses the expertise of many disciplines: vascular surgery, angiology, dermatology, general surgery, interventional radiology and many more. Also in different geographical areas phlebology is generally practiced by very different professionals: in Central Europe or in the USA it has always been practiced mostly by dermatologists as in many other countries is mainly practiced by surgeons.

A peculiarity of phlebology is that with relatively little equipment you can make a high level phlebology that is highly profitable for those who practice it.

Furthermore, most of the phlebological activities may be performed in an office setting, with a possible widespread diffusion. The gray aspect of phlebology is, at the opposite, that every physician making a sclerotherapy or a bandage may consider himself as an expert without a true and extended knowledge.

This explains the stagecoach that we have seen to what until a few decades ago it was considered the Cinderella of vascular diseases.

In this situation it is needed to respond appropriately to the questions with which I began this editorial.

In US it was established in 2007 the American Board of Venous and Lymphatic Medicine (ABVLM; http://www.abvlm.org) that certifies the phlebologist after a training course and an examination and in some countries such as Argentina phlebology is the subject of university education (in Buenos Aires, for example, there is a Chair of Phlebology; http://medi.usal.edu.ar/medi/flebologia-cursouniversitario-flebologia-eco-doppler-color). The Australasian College of Phlebology has three specific programs of training and certification, the Basic phlebology Training which lead to the title of certified sclerotherapist, a two years course diploma and the Advanced Phlebology Training with which the status of fellowship is achieved (http:/www.phlebology. com.au). The training program is both theoretical and clinical with a minimum of procedures that must be performed by the trainee. In 2010 the International Union of Phlebology (UIP) has proposed its curriculum of phlebology ${ }^{1}$ but in Europe there is not currently a precise answer to the request for qualification in phlebology.

The European College of Phlebology (ECoP) has been recently established in order to write common phlebological guidelines and to standardize education and training. For this reason the ECoP has supported the creation of a multidisciplinary commission at the European Union for Medical Specialists (UEMS). ${ }^{2}$ In Italy the Italian College of Phlebology (CIF) is proposing the evaluation of the practitioner made by an anonymous commission, which should determine the skill of the phlebologist; ${ }^{3}$ the Italian Society of Clinical and Experimental Phlebology (SIFCS) is advocating a school of excellence and a certificate of phlebology (http://www.phlebologycourses.org). Courses organized by scientific societies or universities or even private organizations (http://www.valet.it) are available but there is not a real shared path in the various European countries leading to the definition of a professional phlebologist.

In order to overcome this situation the European Registry of phlebologists has been recently established with the initial participation of Italy, Germany, Portugal, Hungary, Poland, Greece Romania and Czech Republic. Those countries have or are organizing corresponding national registries and the project is open to all European countries. In Italy the Registro Italiano dei Flebologi is jointly sponsored by Italian Phlebological Association (AFI) and Italian Society of Phlebology (SIF). The register is to certify the training of the physician and to verify the possible lack of training in the various aspects of the phlebological practice (http://www.registroitalianoflebologi.it).

By the inclusion in the registry he or she will be able to acquire the title of professional phlebologist which will be guaranteed by the inclusion of this category in the ESCO catalog (European classification of skills/competences, qualifications and occupations).

All these similar but inhomogeneous attempts to achieve the target of the phlebologist qualification although demonstrating the
Correspondence: Alessandro Frullini, Associazione Flebologica Italiana (AFI), Piazza Caduti di Pian d'Albero 20, 50063 Figline Valdarno (FI), Italy.

Tel.: +39.055.9157158.

E-mail: a.frullini@associazioneflebologicaitaliana.it

Received for publication: 12 February 2015.

Revision received: 16 February 2015.

Accepted for publication: 19 Februaruy 2015.

This work is licensed under a Creative Commons Attribution 3.0 License (by-nc 3.0).

(C) Copyright A. Frullini, 2015

Licensee PAGEPress, Italy

Veins and Lymphatics 2015; 4:5095

doi:10.4081/vl.2015.5095

great difficulty in finding a common pathway among European countries, however testify a strong desire of giving to phlebology the independence it deserves.

I think that a specific (and shared among European countries) training program on the model of the Australasian College of Phlebology will be the best way to form the European phlebologist and I really hope that in the boundaries of the ECoP this will be achieved in the future, but for now the Registry of Phlebologist remains, at least in my opinion, the best way to define the European phlebologist.

\section{References}

1. Parsi K, Zimmet S, Allegra C, et al. International Union of Phlebology. Phlebology training curriculum. A consensus document of the International Union of Phlebology (UIP) - 2010. Int Angiol 2010;29:533-59.

2. Wittens CHA, Neumann HAM, Rabe E, Davies AH. The future of phlebology in Europe. Phlebology 2013;28:121.

3. Collegio Italiano di Flebologia. Certificazione di qualita del professionista in flebologia; 2014. Available from: http://www.collegioitalianodiflebologia.it/h ccpcif/gest/private/index.php?p=informativa 